\title{
The biological quantitative reduction experimental research on aerobic excess sludge in papermaking wastewater
}

\author{
Jing Liu ${ }^{1}$, Guiju $\mathrm{Li}^{2}$ \\ College of Marine Science \& Engineering, Tianjin University of \\ Science \& Technology,Tianjin,China
}

\begin{abstract}
This paper research aerobic excess sludge come from A / $O$ process in sewage treatment plant of a paper mill in Shandong, china. The content of TCOD, SCOD, TSS, VSS, $\mathrm{PO}_{4}{ }^{3-}-\mathrm{P}$ and $\mathrm{NH}_{4}{ }^{+}-$ $\mathbf{N}$ in this sludge is studied,while, the feasibility that aerobic excess sludge and papermaking wastewater in the same time. The results showed that the theoretical gas production is $1.2 \mathrm{~m}^{3} / \mathrm{VSS} . \mathrm{kg}$ in mesophilic digestion; The release of $\mathrm{PO}_{4}{ }^{3-}-\mathrm{P}$ and $\mathrm{NH}_{4}{ }^{+}-\mathrm{N}$ achieve the best emissions in $\mathrm{pH} 7.0 \sim 8.0$. Within 20 days of continuous experiment, the release of $\mathrm{PO}_{4}{ }^{3-}-\mathrm{P}$ and $\mathrm{NH}_{4}{ }^{+}-\mathrm{N}$ comes from aerobic excess sludge is $1.5 \mathrm{mg} / \mathrm{L}$ and $5.0 \mathrm{mg} / \mathrm{L}$, respectively. The SCOD increase 50-100 $\mathrm{mg} / \mathrm{L}$, in this process. The treatment efficiency of papermaking wastewater is not greater impacted. The release of $\mathrm{PO}_{4}{ }^{3-}-\mathrm{P}$ and $\mathrm{NH}_{4}{ }^{+}-\mathrm{N}$ in this process can replace the added urea and phosphate in water treatment water treatment.
\end{abstract}

Keywords - Papermaking wastewater, anaerobic sludge, quantitative reduction

\section{INTRODUCTION}

The treatment of waste paper making Wastewater generally has a large number of high moisture content of sludge, which must be off as much as possible before final disposal to enhance the solid, in order to further be treated. After treated by physicochemical, biological and chemical methods, more than $90 \%$ suspended solids became sludge [1]. Because aerobic sludge containing a large number of biodegradable ingredients, so when treat the aerobic sludge and wastewater at the same time they can reduce of sludge, Therefore, this method, which can deal with these sludge, benefit for the enterprises and social. It has a certain significance study.

\author{
Haiyang Zhang ${ }^{3}$ \\ Merit Technologies INC（Beijing）,China
}

Since the 80 's, more and more foreign country had to study the stage of hydrolysis in anaerobic digestion [2]. Most of them generate VFA by fermented and hydrolyzed the primary sedimentation sludge which come from Sewage Treatment Plant, others study the sludge mixed by primary sludge and excess sludge [3-5]. The majority of domestic research the acid hydrolysis of high concentration wastewater.There is little study about the sludge comes from municipal wastewater, directed at the treatment plant less acidogenic study [6], not to mention the sludge comes from papermaking.

The $\mathrm{pH}$ is one of important parameters in the anaerobic fermentation. Many researchers found that the sludge after the alkali treatment or the adjusted the $\mathrm{pH}$ over 8.0 can increase the hydrolysis rate of sludge. Vlyssides [7] found that the sludge, after $10 \mathrm{~h}$ treat, when $\mathrm{pH}$ adjusted to 11.0, and temperature is $90{ }^{\circ} \mathrm{C}$, the solubility COD (soluble chemical oxygen demand, SCOD) reached $70000 \mathrm{mg} / \mathrm{L}$. Which is more than $90 \%$ of the total COD (total chemical oxgen demand, TCOD) .This paper mainly study the law of SCOD、V FA、 $\mathrm{PO}_{4}{ }^{3-}-\mathrm{P}$ and $\mathrm{NH}_{4}{ }^{+}-\mathrm{N}$, when anaerobic ferment the excess sludge. in $36 \sim 38{ }^{\circ} \mathrm{C} \mathrm{pH}$ of $4.0 \sim 11.0$.

\section{METHOD OF TEST AND ANALYSIS}

\section{test device and operation}

DF-2 type constant agitator and TF-1 A-type biochemical incubator are used in the study. A $0.5 \mathrm{~L}$ cone-shaped bottle with hose was place in the which the test device, Temperature 36 $38{ }^{\circ} \mathrm{C}$, which simulation anaerobic reactor (ANAMET) used in the factory. Turn speed on $60 \sim 70 \mathrm{r} / \mathrm{min}$, in order to mixed evenly, not to have a whirlpool. Anaerobic reaction is $15 \mathrm{~d}, 2$ 
$\mathrm{mol} / \mathrm{L} \mathrm{NaOH}$ or $2 \mathrm{~mol} / \mathrm{L} \mathrm{HCl}$ are used to adjust $\mathrm{pH}$. During the stagere gulate $\mathrm{pH}$ per 12 hours, keeping $\mathrm{pH}$ in the range of between $0 \sim 0.3$.

2.2 The sources and characteristics of aerobic excess sludge The characteristics of excess sludge come from middle part waterworks in a paper mill. in Table 1.

TABLE 1 CHARACTERISTICS OF THE EXCESS ACTIVATED SLUDGE/MG $\cdot \mathrm{L}$

\begin{tabular}{ccc}
\hline project & average & standard deviation \\
\hline $\mathrm{pH}$ & 7.32 & 0.2 \\
$\mathrm{TSS}$ & 9580 & 621 \\
$\mathrm{VSS}$ & 6969 & 121 \\
$\mathrm{SCOD}$ & 285 & 18 \\
$\mathrm{TCOD}$ & 10566 & 585 \\
$\mathrm{BOD}_{5}$ & 4115 & 410 \\
$\mathrm{PO}_{4}{ }^{3-}-\mathrm{P}$ & 0.38 & 0.3 \\
$\mathrm{NH}_{4}{ }^{+}-\mathrm{N}$ & 4.5 & 1.2 \\
\hline
\end{tabular}

\section{Determination method}

The $\mathrm{pH}$, TSS (total suspended solids), VSS (volatile suspended solids), SCOD, TCOD, BOD $5, \mathrm{PO}_{4}{ }^{3-}-\mathrm{P}, \mathrm{NH}_{4}{ }^{+}-\mathrm{N}$, according to the latest compilation of environmental standards in China. VFA (volatile fatty acid) is exterminated by Acid-base titration.

\section{The calculation of oretical gas production}

The gas made by fermented Sludge is methane, which major components of $\mathrm{CH}_{4}$ and $\mathrm{CO}_{2}$. Under normal circumstances, other gases (such as $\mathrm{N}_{2}, \mathrm{H}_{2}, \mathrm{H}_{2} \mathrm{~S}, \mathrm{O}_{2}$ ) very little content, which may be negligible. Assumed that in the sludge digestion process, all the loss carbon transformed $\mathrm{CH}_{4}$ and $\mathrm{CO}_{2}$, according to carbons' material conservation and Moshi curve, in order to find that under the conditions of mesophilic digestion, the relationship between organic content and decomposition rate, which can calculation of oretical gas production.

The density of $\mathrm{CH}_{4}$ and $\mathrm{CO}_{2}$ gas are $0.7168 \mathrm{~g} / \mathrm{L}$ and gas $1.9769 \mathrm{~g} / \mathrm{L}$, respectively, while the carbon content in them are $0.5367 \mathrm{~g} / \mathrm{L} 、 0.5395 \mathrm{~g} / \mathrm{L}$, respectively . The gas is making up of $75 \% \mathrm{CH}_{4}$ and $25 \% \mathrm{CO}_{2}$. According to this, the gas came from TOC which can be decomposed in can produce $1.861 \mathrm{~L} / \mathrm{g}$. The organic compounds in this sludge is $72.75 \%$ and decomposing rate is $71.0 \%$, the TOC in VSS is $55 \%$.So that the gas comes from this experimental is $5.0 \mathrm{~m}^{3} / \mathrm{m}^{3}$.VSS..

\section{RESULTS}

The impact of temperature to gas production

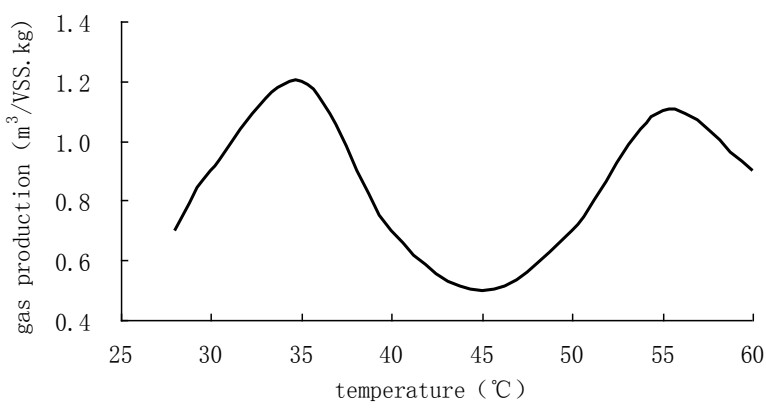

Figure 1 Correlation between temperature and gas production

From Figure 1, methane production in a wave band changes with temperature. There is a largest gas production $1.2 \mathrm{~m}^{3} / \mathrm{VSS} . \mathrm{kg}$, in the mesophilic digestion. With increasing temperature, is declining, there is smallest value in $45{ }^{\circ} \mathrm{C}$. When the temperature continues to rise, in $55{ }^{\circ} \mathrm{C}$ gas production is the same as that in $45{ }^{\circ} \mathrm{C}$.The anaerobic reactor (ANAMET)in paper mill has a better effect in $34 \sim 36^{\circ} \mathrm{C}$, so that the temperature in this experiment is sat in $34 \sim 36^{\circ} \mathrm{C}$.

\section{The impact of $\mathrm{pH}$ to $\mathrm{PO}_{4}^{3-}-\mathrm{P}$}

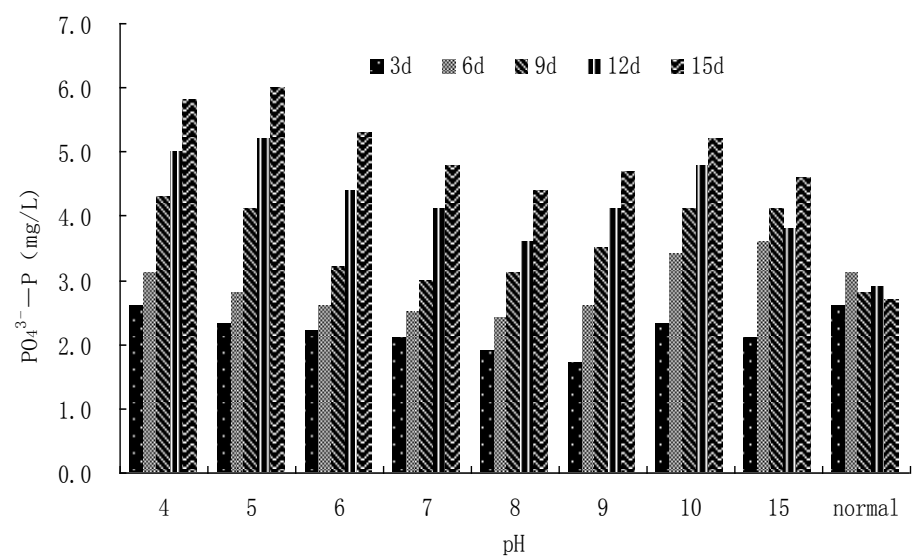

Fig. 2 Changes of $\mathrm{PO}_{4}{ }^{3-}-\mathrm{P}$ at different $\mathrm{pH}$ (within 15d)

From Figure 2, we can find that under acidic conditions, the $\mathrm{PO}_{4}{ }^{3-}-\mathrm{P}$ is slightly higher than alkaline. In near neutral conditions $(\mathrm{pH}=7.0$ and $\mathrm{pH}=8.0)$, the $\mathrm{PO}_{4}{ }^{3-}-\mathrm{P}$ concentrations 
have a minimum, which is same as in the normal conditions. The $\mathrm{PO}_{4}{ }^{3-}-\mathrm{P}$ have a same trend in $\mathrm{pH}=9.0$ and $\mathrm{pH}=11.0$. There is a maximum value on $\mathrm{pH}=5$.0. In addition, except for the normal $\mathrm{pH}$, the dissolution of $\mathrm{PO}_{4}{ }^{3-}-\mathrm{P}$ essentially increased. with the anaerobic fermentation time.

The impact of pH to $\mathrm{NH}_{4}^{+}-\mathrm{N}$

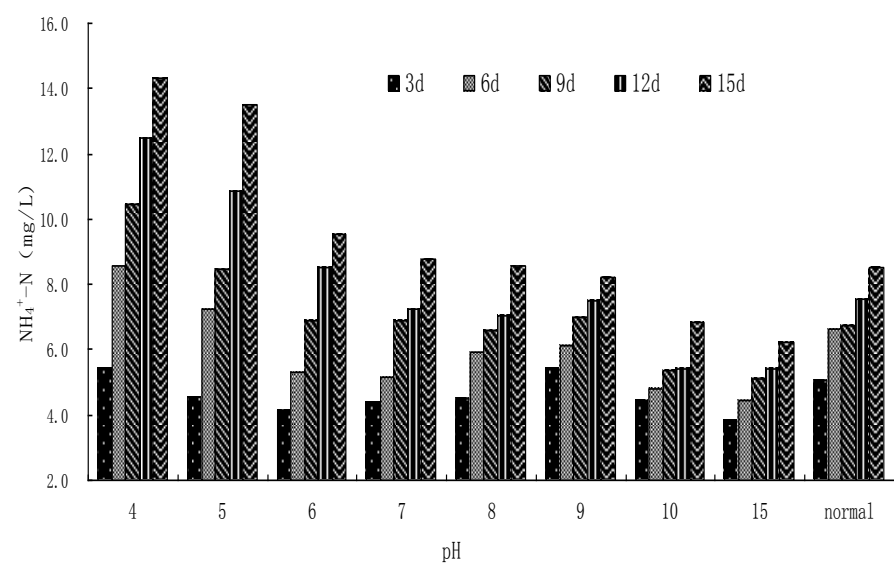

Fig. 3 Changes of $\mathrm{NH}_{4}{ }^{+}-\mathrm{N}$ at different $\mathrm{pH}$ (within 20d)

The dissolution of $\mathrm{NH}_{4}{ }^{+}-\mathrm{N}$ in Figure 3 is similar with $\mathrm{PO}_{4}{ }^{3-}$ -P in Figure 2, which different is that there is a maximum value $\mathrm{pH}=4.0$ and the dissolution of the $\mathrm{NH}_{4}{ }^{+}-\mathrm{N}$ have changed little with anaerobic fermentation time.

\section{The release of the $\mathrm{PO}_{4}{ }^{3-}-\mathrm{P}$ in continuous culture}

In the pre-anaerobic wastewater experiment we found that the best $\mathrm{pH}$ value is range of $7.0 \sim 7.5$. In order to achieve the aerobic wastewater sludge and the best treatment effect, the experiment of continuous culture without adjustment $\mathrm{pH}$.This experiment simulated the actual, adding 15 days of aerobic sludge production in the anaerobic sludge, adding fresh water to the paper continuous culture experiments every day. The changes of $\mathrm{PO}_{4}{ }^{3-}-\mathrm{P}$ with culture times and changes of COD with culture times in Figure 4.

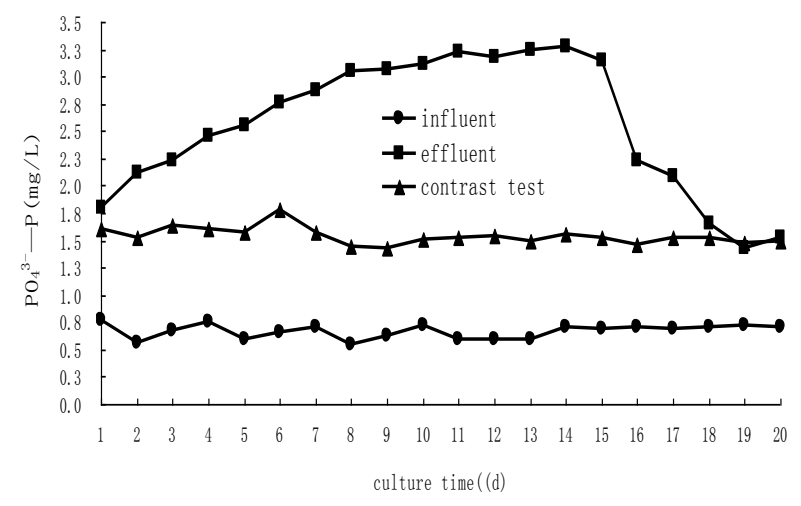

Figure 6 Changes of $\mathrm{PO}_{4}{ }^{3-}-\mathrm{P}$ with culture times

As can be seen from Figure 4, the $\mathrm{PO}_{4}{ }^{3-}-\mathrm{P}$ in influent is about $0.6 \sim 0.8 \mathrm{mg} / \mathrm{L}, \mathrm{PO}_{4}{ }^{3-}-\mathrm{P}$ in effluent significant changed in the three stages. The first stage is 1-9 days, the $\mathrm{PO}_{4}{ }^{3-}-\mathrm{P}$ has a faster rate, from $1.8 \mathrm{mg} / \mathrm{L}$ to $3.0 \mathrm{mg} / \mathrm{L}$; the second phase for 10-15 days, the release $\mathrm{PO}_{4}{ }^{3-}-\mathrm{P}$ at this time have a slow pace of growth, after 12 days $\mathrm{f}$ the release of $\mathrm{PO}_{4}{ }^{3-}-\mathrm{P}$ is $3.2 \mathrm{mg} / \mathrm{L}$, which is as 3 times as that in influent, reach stability. The third stag is 16-20 days, in which the $\mathrm{PO}_{4}{ }^{3-}-\mathrm{P}$ apparent downward trend in effluent.This phenomenon mainly because that we just 15 days aerobic excess sludge. With the reaction time, most of the $\mathrm{PO}_{4}{ }^{3-}-\mathrm{P}$ has been released a few of them residued. So that in 16-18 d, there is a small of the $\mathrm{PO}_{4}{ }^{3-}-\mathrm{P}$ release. The release of $\mathrm{PO}_{4}{ }^{3-}-\mathrm{P}$ in contrast text also has the same trend.In addition $\mathrm{PO}_{4}{ }^{3}-\mathrm{P}$ in content is as 2 times as that in influent, which is probably response to the microbial in anaerobic sludge phosphorus accumulating in release in their life then release in the experimen [8].

\section{The release of $\mathrm{NH}_{4}{ }^{+}-\mathrm{N}$ in continuous culture}

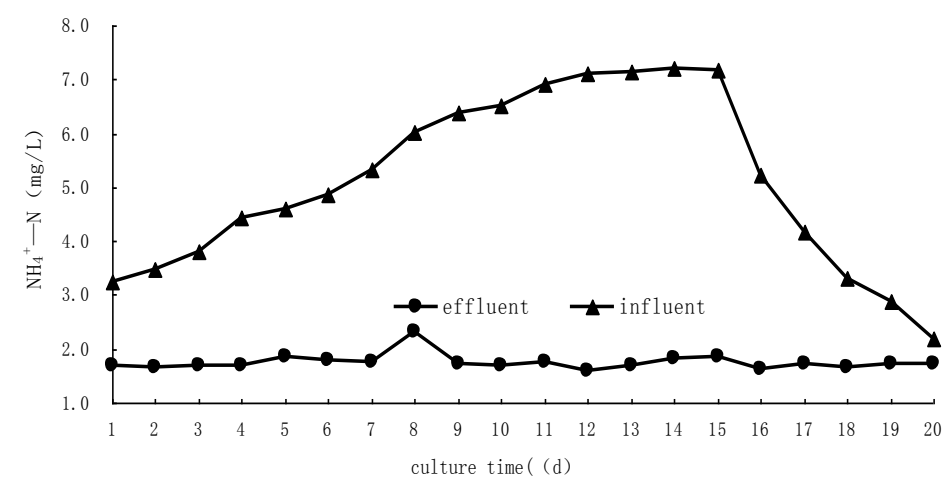

Figure 5 Changes of $\mathrm{NH}_{4}^{+}-\mathrm{N}$ with culture times 
As can be seen from Figure 5, the $\mathrm{NH}_{4}{ }^{+}-\mathrm{N}$ in influent is $1.60 \sim 2.2 \mathrm{mg} / \mathrm{L}$, while the $\mathrm{NH}_{4}{ }^{+}-\mathrm{N}$ in effluent also showed three changes in trend and also positively correlated with the increase of SCOD .The release of $\mathrm{NH}_{4}{ }^{+}-\mathrm{N}$ has a stability value that about $7.1 \mathrm{mg} / \mathrm{L}$ in the12th day, which is as 4 times as that in influent.This phenomenon is mainly due to the $\mathrm{NH}_{4}{ }^{+}-\mathrm{N}$ has a high value that is $4.5 \mathrm{mg} / \mathrm{L}$ in aerobic excess sludge.

In short, the research of hydrolysis and fermentation of activated sludge is still in the preliminary stages of the phenomenon described, and its mechanism of acid production, the impact of emissions factors in $\mathrm{PO}_{4}{ }^{3-}-\mathrm{P}$ and $\mathrm{NH}_{4}{ }^{+} \mathrm{-N}$ and the key mechanism of micro-organisms still need further study .

\section{CONCLUSIONS}

A. In the process of $\mathrm{pH}$ impact to the experiment, the release of $\mathrm{PO}_{4}{ }^{3-}-\mathrm{P}$ and $\mathrm{NH}_{4}{ }^{+}-\mathrm{N}$ increased with the fermentation time. Extreme $\mathrm{pH}$ values $(\mathrm{pH}=4.0$ and $\mathrm{pH}=11.0)$ are not conducive to VFA.

B. In course of 20-days continuous culture, $\mathrm{PO}_{4}{ }^{3-}-\mathrm{P}$ and $\mathrm{NH}_{4}{ }^{+}-\mathrm{N}$ emissions, which has positive correlation with the increase in SCOD, were both have three changes trend and have stable value in 11 days.

C. In achieve stability, the release of $\mathrm{PO}_{4}{ }^{3-}-\mathrm{P}$ is $3.2 \mathrm{mg} / \mathrm{L}$ that is two times of the contrast text. While the release of $\mathrm{NH}_{4}{ }^{+}-\mathrm{N}$ is about $7.0 \mathrm{mg} / \mathrm{L}$ that is four times of the contrast text. So that we can concluded that aerobic excess sludge can be used in place of the actual process of addition of $\mathrm{N} 、 \mathrm{P}$, which can reduce the cost of inputs, reducing the cost of the remaining sludge treatment.

\section{REFERENCE}

[1] WU Xiang-bo, XIE Yi-min. The technology of treatment and disposal the sludge in regenerated papermaking [J] .jiangsu papermaking,2008,3: 40-43

[2] YUAN Hong-ying, ZHANG Hua-xing, CHEN Yin-guang, ZHOU Qi .Impact of $\mathrm{pH}$ on the Generation of COD, Phosphorous and Ammonia-Nitrogen During the Anaerobic Fermentation of Excess Activated Sludge [J]. ENVIRONMENTAL SCIENCE. 2006,27 （7）:1358-1359
[3] Banerjee A, Elefsiniotis P, Tuhtar D. The effect of addition of potato-processing wastewater on the acidgenesis of primary sludge under varied hydraulic retention time and temperature [J]. Biotechn, 1999,72:203-212.

[4 ] Hatziconstantinou G J, Yannakopulos P, Andreadskis A Primary sludge hydrolysis for biological nutrient removal[J], Wat. Sci. Tech., 1996,34(2):417-423.

[5] Moser-Engeler R, Udert K M, Wild D,et al. Products from primary sludge fermentation and their suitability for nutrient removal[J]. Wat. Sci. Tech., 1998,38(1):265-273.

[6] SHAO Pei-hong,et al. Experimental research on highefficiency hydrolysis-acidogenosis test[J]. Charychun Inst. Tech.(Nal. Sci. Edi.), 2004,5(1):15-17.

[7] Vlyssides A G, Klarlis P K. Thermal-alkaline solubilization of waste activated sludge as a pre-treatment stage for anaerobidigestion [J]. Bioresource Technology, 2004,91:201206.

[8 ] Rustrian E, Delgenes J P, Moletta R. 1997. Phosphate Release and up take by pure cultures of acinetobacter sp: effect of the volatile fatty acids concentration [ J ]. Current Microbiology, $34(7): 43-48$ 